\title{
Small business barriers to occupational health and safety compliance
}

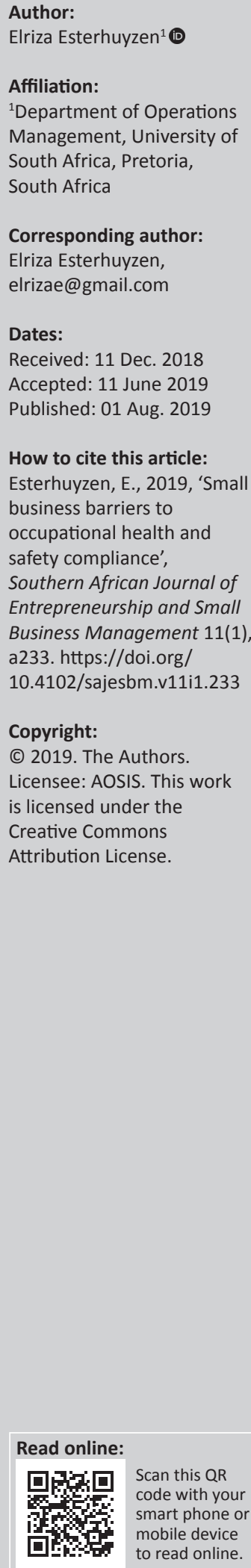

Background: The Constitution of South Africa indicates that all people have the right to an environment that is not harmful to their health and well-being. This right is reiterated in the Occupational Health and Safety Act 83 of 1993. However, small business owners and/or managers experience specific barriers to occupational health and safety (OHS) compliance. The study was conducted in Gauteng, KwaZulu-Natal and the Western Cape provinces of South Africa, as these three provinces account for $82 \%$ of active businesses in South Africa.

Objective: This article discusses barriers to OHS compliance as perceived by South African small business owners and/or managers.

Method: A total of 350 small business owners and/or managers from the three abovementioned provinces participated in a questionnaire survey, with one section focussing on barriers to OHS compliance. Participants rated 11 predetermined barriers to OHS compliance and could indicate and rate additional barriers. Descriptive and inferential statistics were used to report on these perceived barriers.

Results: Results indicated that the perceived barriers to OHS compliance can be categorised as human and resource barriers.

Conclusion: South African small business owners and/or managers experience barriers to compliance that prevent them from full compliance with OHS directives, which can be costly. Small business owners and/or managers need to take cognisance of applicable OHS directives as well as identified barriers to compliance. These barriers need to be addressed to allow small businesses to comply with OHS directives and to enhance the sustainability of small businesses. The question is not whether small businesses can afford OHS compliance, but if they can afford not to overcome barriers and comply.

Keywords: Small business; occupational health and safety; OHS; barriers to occupational health and safety compliance; South Africa.

\section{Introduction}

The South African National Development Plan emphasises the importance of establishing and growing small businesses. These enterprises are expected to contribute significantly to the growth of the South African economy and the resultant reduction of unemployment (National Planning Commission 2014:9). However, an increase in the workforce also has financial implications with regard to occupational injuries and illnesses. Small businesses can thus ill afford cost-saving with regard to occupational health and safety $(\mathrm{OHS}$ ) as OHS legal compliance is emphasised (Ahonen \& Hussi 2012:4). All employees enjoy the benefit of the Constitution of South Africa that stipulates the right to perform their duties in a safe working environment that is not harmful to their health and safety (Mojapelo \& Kok 2017:55).

Small businesses are considered major contributors to the economic activity in a country (Struwig \& Lillah 2017). Even though small businesses in South Africa are not always registered and regulated (Henning \& Akoob 2017), such businesses should still comply with OHS legislation. The number of accidents in South Africa because of poor levels of adherence to relevant health and safety regulations is deemed to be high, with such accidents negatively impacting the State, employers and employees (Mojapelo \& Kok 2017:58). It is important to understand the challenges that small businesses face in order to enhance their contribution to economic development (Van Vuuren \& Alemayehu 2018). This article, therefore, reports on identifying the perceived barriers to OHS compliance as experienced by small business owners and/or managers in South Africa as well as the relationship between such barriers and compliance behaviour. 
As in the case of any other business, small businesses must comply with various legal requirements pertaining to $\mathrm{OHS}$ in the workplace. Too many laws, however, are killing small businesses (Kent 2013:1) and challenges relating to their OHS compliance are often ascribed to lack of financial resources, insufficiency of managerial skills and poor commitment (Floyde et al. 2013:70). Accidents in the workplace cause serious financial and non-financial problems for both employees and businesses (Mojapelo \& Kok 2017:51). Legal obligations pertaining to OHS in small businesses have been indicated as important factors related to limiting unnecessary costs associated with occupational injuries, illnesses and fatalities (Maxey 2013:12). Both social and economic implications of OHS for individuals, families and communities are globally indicated as major concerns (Hermanus 2007:53) Thus OHS legal requirements are receiving increasing attention in most countries (Chen \& Zorigt 2013:2321). The successful management and the financial growth of small businesses, in particular, are in part dependent upon full recognition and implementation of OHS directives as specified in applicable legislation (Okoye \& Okolie 2014:21); this is despite limited financial and a managerial resources with regard to OHS (Hasle, Kines \& Andersen 2009). Research has indicated that small business owners and/or managers need sufficient knowledge and a positive attitude towards OHS as well as the behavioural intent to comply with OHS directives (Esterhuyzen 2017). However, even though all of these factors might be present, there are barriers that can hinder OHS compliance (Esterhuyzen 2017:11). In order to move from intentional behaviour to actual behaviour, barriers to compliance need to be identified and addressed (Probst et al. 2013). In identifying the barriers to OHS compliance, guidelines can be set for future improvement in this regard with a view to enhancing competitiveness (Stranks 2010:137-138) as well as to reducing the costs associated with accidents (Mojapelo \& Kok 2017:58).

\section{Literature review}

\section{Barriers to occupational health and safety compliance}

Businesses, regardless of their size, should have an unwavering commitment to compliance and enforcement (Markowitz \& Gerardu 2012:540-553). However, small businesses in particular are faced with very specific challenges pertaining to the management of health and safety (Starren, Hornikx \& Luijters 2013:42).

Behavioural control refers to the perception of how easy or difficult it is to display a certain behaviour, with barriers adversely influencing the intention of desired behaviour (Struwig \& Lillah 2017). Challenges pertaining to the management of health and safety in small businesses include limited resources, inadequate guidance and advice, the lack of a holistic approach to the integration of OHS into business operations, insufficient training opportunities, deficient development of OHS competency, and a lack of cooperation between employers and employees (Hermanus 2007:538).
Relevant literature also points to negligence, carelessness, not adhering to safe working procedures, unskilled employees, and lack of supervisors or skilled supervisors as barriers to compliance with OHS directives (Othman 2012:190). The issue of small business owners and/or managers who lack proper knowledge and experience about OHS directives and who do not have the appropriate attitude or motivation related to OHS is also included as a barrier to OHS compliance (Ajzen \& Sheikh 2013:156; Probst et al. 2013:126). Rules that are not practically workable, unrealistic, too time consuming, and too numerous to maintain may lead to people working to rule and not working safely. Such a position might result in a barrier to OHS compliance. Furthermore, individual as well as organisational factors can serve as barriers to $\mathrm{OHS}$ compliance. Individual factors include a lack of planning, self-image and status, whereas organisational factors include oversights and time pressure (Hale \& Borys 2013:208-212). This state of affairs might be exacerbated by group factors such as an emphasis on production rather than OHS as well as ignoring safety risks and the misapplication of effective working rules (Reason 2005:17, 2007:75-78).

\section{Cost of non-compliance with occupational health and safety directives}

The health and safety of employees is not negotiable (Mashwama, Aigbavboa \& Thwala 2018). Employers should comply with applicable OHS directives with a view to implementing sufficient health and safety standards in their businesses (Mojapelo \& Kok 2017:54). Such health and safety standards are aimed at avoiding or mitigating the risks of injuries and other types of psychological and physical harm to employees (Wilson 2018). Regardless of the industry in which a business operates or the size of the business, OHS is an essential part of business management practices and should not be neglected or regarded as an unnecessary expense. Small businesses are indicated as having additional challenges pertaining to OHS because of factors such as noncompliance with preventive interventions indicated in OHS directives, economic pressure and extended working hours as well as ignorance regarding relevant $\mathrm{OHS}$ directives (Mayhew 2000:300-301).

The South African Department of Labour has stated the importance of compliance with OHS requirements with a view to saving resources necessary for job creation and sustainable development (DoL 2013). Such sustainable development requires control over direct and indirect costs pertaining to OHS, which relies on good governance as determined by the rule of law, which, in turn, rests on effective compliance and enforcement (Markowitz \& Gerardu 2012:540). Direct costs associated with OHS are those related to damage to machinery, damage claims, legal costs, medical treatment of injured and ill employees, and increased insurance premiums (Fuller \& Vassie 2004:136). Indirect costs associated with OHS are those related to loss of income (Hermanus 2007:531), finding and training of replacements for ill or injured employees, retraining of employees and damage to the image of the business (Goetsch 2014:19-27). 
Direct and indirect costs associated with OHS place a considerable burden on businesses and government, with the International Labour Organization attributing losses of around $4 \%$ of the world's gross domestic product to such costs (Niu 2010:744; International Labour Organization 2014:3). Businesses that do not comply with OHS directives may provide conditions in the workplace that threaten the health, well-being and working capacity of employees, thus affecting the quality of working life and the economic status of employees as well as their families because of direct and indirect costs associated with OHS (WHO 2007:77, 2017:1). The ratio between direct and indirect costs of OHS-related accidents and incidents in South Africa is estimated to be at about 1:7 (Pillay 2014:6). Small business compliance with OHS directives and resultant OHS measures lead to a reduction in direct and indirect costs associated with OHS, thus contributing to an increase in both production and economic welfare of the business to enhance sustainable development (Markowitz \& Gerardu 2012:553; Mashwama et al. 2018; Semboja, Ahonen \& Hussi 2012:9).

Non-compliance with applicable OHS directives can lead to penalties and fines. In addition, a business that is found guilty of not complying with OHS directives suffers more than financial penalties. The trust and credibility of such a business can be seriously compromised, thus requiring resources to restore its damaged reputation. It is therefore suggested that businesses, including small businesses, provide the highest possible working standards for their employees and invest in solutions that can help them to carry out their OHS duties within the applicable legal framework.

\section{Research design and methodology}

Data were collected via a questionnaire. This questionnaire was designed and developed based on the constructs applicable to the barriers to OHS compliance in small businesses. A homogeneous purposive sampling technique was used to select the sample for this study which limited the respondents pool according to the requirements for a small business as defined for this study (an annual turnover of less than R50 million and fewer than 50 employees) This nonprobability sample was extended via the snowballing and referral technique in order to recruit qualifying respondents from the acquaintances of respondents, with the sample consisting of 350 small business owners and/or managers from three provinces in South Africa which hosted the highest number $(81.8 \%)$ of active businesses. These three provinces are Gauteng, the Western Cape and KwaZuluNatal (CIPC 2013:3). Two fieldworkers were trained, assessed and declared competent by the researcher. Thereafter, these two fieldworkers took the questionnaire to qualifying small business owners and/or managers in the identified provinces. The fieldworkers ensured that the predetermined number of questionnaires per province, as indicated in Table 1, was completed and that fully completed questionnaires were received.
The questionnaire was drafted and refined using a flowchart for questionnaire design indicated by Cooper and Schindler (2011:338). The questionnaire included filter questions to screen respondents, followed by target questions related to barriers to OHS compliance. Forced-choice scale questions were used and respondents required to rate barriers to OHS compliance on a Likert-type rating scale. The respondents had to rate barriers to OHS compliance as: (1) not a barrier, (2) somewhat of a barrier, (3) moderate barrier, or (4) extreme barrier, with an additional option of (5) do not know. In addition, respondents were provided with the opportunity to add additional barriers and to rate such barriers according to the same rating scale. The questionnaire was pre-tested by a group consisting of two small business owners and/or managers, two academics, two fieldworkers, and a statistician. Particular attention was paid to the confirmation of reliability of the questionnaire. Reliability testing through statistical analysis of the pre-test results confirmed reliability and internal consistency. Data were collected from December 2015 to April 2016, with a response rate of 70\%. Data analysis included both descriptive and inferential statistics, such as exploratory factor analysis and Pearson product-moment correlations.

\section{Ethical consideration}

Ethics approval was obtained from the Department of Business Management, UNISA Ethics Committee, reference number 2015_CRERC_039(FA). The participants' right to privacy and anonymity was respected, and participants were informed of their right to withdraw at any stage while completing the questionnaires.

\section{Survey results Demographic information}

Table 1 summarises the demographic information related to the survey. Screening questions were included in the questionnaire to ensure: that each participant was the owner or manager of the small business, that the provincial location of the small business was in the three provinces identified for

TABLE 1: Demographic information of participants.

\begin{tabular}{llc}
\hline Demographic variable & Category & $\mathbf{\%}$ \\
\hline Position in the small business & Owner & 33.4 \\
& Manager & 66.6 \\
Provincial location of the small business & Gauteng & 61.4 \\
& KwaZulu-Natal & 17.7 \\
& Western Cape & 20.9 \\
Annual turnover of the small business & Less than R10 million per year & 100.0 \\
Number of employees & $1-5$ & 53.5 \\
& $6-10$ & 24.0 \\
& $11-15$ & 11.4 \\
Primary economic sector & $16-49$ & 11.1 \\
& Manufacturing and construction & 22.0 \\
& Wholesale and retail & 30.3 \\
& Repair and maintenance & 27.4 \\
\hline
\end{tabular}

Source: Adapted from Esterhuyzen, E., 2017, 'Occupational health and safety: A compliance management framework for small businesses in South Africa', PhD thesis, Department of Business Management, University of South Africa, Pretoria 
this study, that the annual turnover of the small business was less than R10 million per year and that the number of employees was less than 50. The participants also indicated the primary economic sectors in which the small businesses operated, with the primary economic sectors combined as indicated in Table 1.

\section{Statistical analysis}

The small business owners and/or managers provided information about specific barriers that might make it difficult to comply with OHS directives. Participants were requested to rate the effects of these barriers on a scale of 1-4. Participants were given two opportunities to provide feedback on barriers to OHS compliance. First, participants rated a list of possible barriers that were identified from relevant literature. Next, they were requested to list and rate their own supplied list of additional barriers to comply with $\mathrm{OHS}$ directives or requirements.

The results of the rating of predetermined barriers are shown in Table 2. As the results indicate, no particular barrier to complying with OHS directives was rated as an extreme barrier. 'Laws are too complicated' was rated the most extreme barrier by only $14.6 \%$ of the participating small businesses. A total of $30.0 \%-56.3 \%$ of small businesses rated 9 out of the total of 11 barriers as not being a barrier at the time of the survey. A group of small businesses ranging from $26.9 \%$ to $56.3 \%$ rated 9 out of the 11 listed directives as not being a barrier. On average, just over a quarter $(26.0 \%)$ of small businesses rated most of the barriers as being somewhat of a barrier.

The following data emerged from the questionnaire as shown in Table 2:

- Less than $10.0 \%$ of small businesses indicated that they did not know whether certain barriers made it difficult to comply with OHS directives.

- On average, less than $10.0 \%$ of the small businesses rated any of the listed OHS directives as an extreme barrier to comply with OHS aspects.

- No particular OHS aspect was listed significantly high as a barrier to comply with OHS directives, as all rates were below $33.0 \%$, which applied to somewhat of a barrier, a moderate barrier, and an extreme barrier.

- The general rating of barriers was approximately 2.0 out of a possible 4.0, which indicated the overall contention of small businesses that no specific aspect made it extremely difficult to comply with OHS directives.

Small business owners and/or managers were asked to list additional barriers which, in their view, affected their compliance with OHS directives. These views involved openended responses and are listed in Table 3. Noteworthy is the challenge to decide on the categorisation of the barriers listed by participants. The challenge was caused by the fact that participants listed some barriers by using a single word without any proper description.

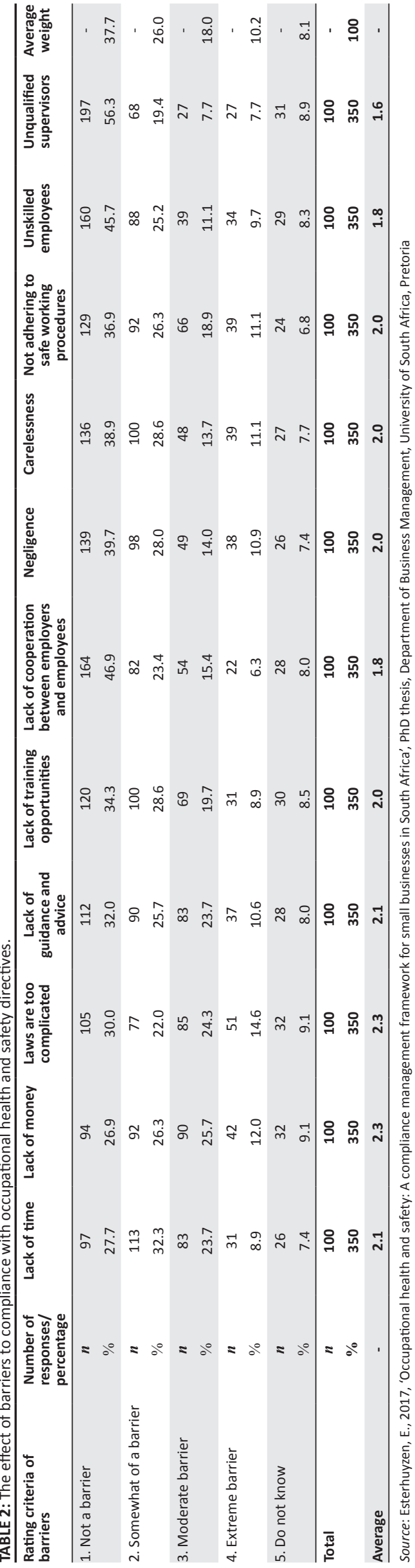


TABLE 3: Participant-listed barriers that affect compliance with occupational health and safety directives.

\begin{tabular}{|c|c|c|c|c|c|c|c|c|}
\hline \multirow[t]{3}{*}{ Barrier to compliance } & \multicolumn{8}{|c|}{ Rating } \\
\hline & \multicolumn{2}{|c|}{$\begin{array}{c}\text { Not a } \\
\text { barrier }\end{array}$} & \multicolumn{2}{|c|}{$\begin{array}{l}\text { Somewhat } \\
\text { of a barrier }\end{array}$} & \multicolumn{2}{|c|}{$\begin{array}{l}\text { Moderate } \\
\text { barrier }\end{array}$} & \multicolumn{2}{|c|}{$\begin{array}{l}\text { Extreme } \\
\text { barrier }\end{array}$} \\
\hline & $n$ & $\%$ & $n$ & $\%$ & $n$ & $\%$ & $n$ & $\%$ \\
\hline Claims are painful & - & - & - & - & - & - & 1 & 3.4 \\
\hline $\begin{array}{l}\text { Lack of knowledge/unskilled } \\
\text { employees }\end{array}$ & - & - & 1 & 25.0 & 1 & 20.0 & 1 & 3.4 \\
\hline Creating or maintaining safety file & - & - & - & - & - & - & 1 & 3.4 \\
\hline $\begin{array}{l}\text { Generating, updating and keeping } \\
\text { records; paperwork }\end{array}$ & - & - & - & - & 1 & 20.0 & 2 & 7.1 \\
\hline $\begin{array}{l}\text { Compensation Commissioner } \\
\text { (inaccessible) }\end{array}$ & - & - & - & - & - & - & 3 & 10.6 \\
\hline Lack of time - hours; time constraints & - & - & 1 & 25.0 & - & - & 2 & 7.1 \\
\hline Language & - & - & - & - & 2 & 40.0 & - & - \\
\hline Stress & - & - & - & - & - & - & 1 & 3.4 \\
\hline Flood - natural disaster & - & - & - & - & - & - & 1 & 3.4 \\
\hline Lack of information & - & - & - & - & - & - & 1 & 3.4 \\
\hline Lack of management and supervision & - & - & - & - & - & - & 1 & 3.4 \\
\hline $\begin{array}{l}\text { No communication from Department } \\
\text { of Labour }\end{array}$ & - & - & - & - & 1 & 20.0 & 1 & 3.4 \\
\hline $\begin{array}{l}\text { Employee unwillingness to comply, a } \\
\text { lack of interest, negative attitude, } \\
\text { negligence of employees }\end{array}$ & - & - & - & - & - & - & 4 & 13.8 \\
\hline Registration with authorities & - & - & - & - & - & - & 1 & 3.4 \\
\hline $\begin{array}{l}\text { Non-workers insist on being in } \\
\text { workshop }\end{array}$ & - & - & - & - & - & - & 1 & 3.4 \\
\hline Time off for training & - & - & 1 & 25.0 & - & - & 1 & 3.4 \\
\hline Laws are complicated & - & - & 1 & 25.0 & - & - & 1 & 3.4 \\
\hline $\begin{array}{l}\text { Difficulty sending incident report to } \\
\text { Compensation Commissioner }\end{array}$ & - & - & - & - & - & - & 1 & 3.4 \\
\hline Abuse of sick leave & - & - & - & - & - & - & 2 & 7.1 \\
\hline $\begin{array}{l}\text { Assessment of employees is time } \\
\text { consuming }\end{array}$ & - & - & - & - & - & - & 1 & 3.4 \\
\hline Resignation of trained employees & - & - & - & - & - & - & 1 & 3.4 \\
\hline Unqualified employees & - & - & - & - & - & - & 1 & 3.4 \\
\hline Training fees extremely exorbitant & - & - & - & - & - & - & 1 & 3.4 \\
\hline Total & - & - & 4 & 100 & 5 & 100 & 30 & 100 \\
\hline
\end{tabular}

Source: Esterhuyzen, E., 2017, 'Occupational health and safety: A compliance managemen framework for small businesses in South Africa', PhD thesis, Department of Business Management, University of South Africa, Pretoria

TABLE 4: Table of total variance explained.

\begin{tabular}{lccc}
\hline Factors & \multicolumn{3}{c}{ Initial eigenvalues } \\
\cline { 2 - 4 } & Total & \% of variance & Cumulative \% \\
\hline Lack of time & 6.021 & 54.740 & 54.740 \\
Lack of money & 1.594 & 14.490 & 69.230 \\
Laws are too complicated & 0.875 & 7.952 & 77.182 \\
Lack of guidance and advice & 0.655 & 5.959 & 83.141 \\
Lack of training opportunities & 0.470 & 4.274 & 87.415 \\
Lack of cooperation between employers & 0.407 & 3.699 & 91.114 \\
and employees & & & \\
Negligence & 0.299 & 2.714 & 93.828 \\
Carelessness & 0.218 & 1.981 & 95.809 \\
Not adhering to safe working procedures & 0.210 & 1.908 & 97.717 \\
Unskilled employees & 0.176 & 1.601 & 99.319 \\
Unqualified supervisors & 0.075 & 0.681 & 100.000 \\
\hline
\end{tabular}

Source: Esterhuyzen, E., 2017, 'Occupational health and safety: A compliance managemen framework for small businesses in South Africa', PhD thesis, Department of Business Management, University of South Africa, Pretoria

The following details were relevant:

- The listing and rating of barriers did not reveal any dominant barrier at any specific level of effect (i.e. 'somewhat of a barrier' through to 'an extreme barrier').

- Small business owners and/or managers listed a range of 23 barriers (38 responses) - where some of these were interrelated.
TABLE 5: Exploratory factor analysis on barriers to occupational health and safety compliance.

\begin{tabular}{lcc}
\hline Barriers to compliance: Items & \multicolumn{2}{c}{ Identified factors } \\
\cline { 2 - 3 } & $\begin{array}{c}\text { Factor 1: Human factors } \\
\text { (factor loading) }\end{array}$ & $\begin{array}{c}\text { Factor 2: Lack of } \\
\text { resources (factor loading) }\end{array}$ \\
\hline Negligence & 0.92 & - \\
$\begin{array}{l}\text { Not adhering to safe working } \\
\text { procedures }\end{array}$ & 0.90 & - \\
Carelessness & 0.89 & - \\
Lack of cooperation between & 0.75 & - \\
employers and employees & & - \\
Unqualified supervisors & 0.74 & - \\
Unskilled employees & 0.70 & 0.87 \\
Lack of guidance and advice & - & 0.82 \\
Laws are too complicated & - & 0.71 \\
Lack of training opportunities & - & 0.64 \\
Lack of money & - & 0.55 \\
Lack of time & - & - \\
\hline Source: Ester & &
\end{tabular}

Source: Esterhuyzen, E., 2017, 'Occupational health and safety: A compliance management framework for small businesses in South Africa', PhD thesis, Department of Business Management, University of South Africa, Pretoria

- Almost three quarters (30 out of $38=76.3 \%$ ) of the list provided by respondents were regarded as 'extreme barriers'.

- The diverse range and rating of barriers seemed to be related to personal experience and choice.

- Very few (only 5 out of $38=13.1 \%$ ) barriers were rated at more than one level of effect ('somewhat of a barrier' through to an 'extreme barrier').

The results indicated that respondents believed that no specific additional barrier seemed to jeopardise their compliance with OHS directives. Therefore, only the 11 predetermined barriers to OHS compliance were analysed further.

The inter-correlation of the barriers to OHS compliance indicated that the data were suitable for factor analysis. Bartlett's test of sphericity $\chi^{2}=2386.63(d f=55 ; p \leq 0.05)$ and the Kaiser-Meyer-Olkin Measure of Sampling Adequacy (at 0.88 , which is more than 0.6 , thus indicating that the data were suitable for factor analysis) indicated the overall significance of correlation within each of the two identified factors (Pallant 2011:192). The chi-square value from Bartlett's test of sphericity was statistically significant $(p \leq 0.05)$ for the barriers to OHS compliance. The initial eigenvalues for the barriers to OHS compliance are indicated in Table 4.

All the 11 barriers to OHS compliance items were used, with two factor loadings proposed based on the number of eigenvalues larger than unity. The percentage of variance explained was 69.23 on two factors, namely human factors and lack of resources. Factor analysis is used to reduce a set of variables to more manageable dimensions or factors based on closely related items (Pallant 2011:104). An exploratory factor analysis was conducted on the barriers of compliance identified in this study to ascertain the grouping ability of these barriers. The results are indicated in Table 5.

The Cronbach's alpha for the human factors was 0.94 and for lack of resources 0.95 , thus indicating reliability. 
Pearson product-moment correlation can be used to explore the relationship between continuous variables to obtain an indication of the direction, as well as the strength of the relationship (Pallant 2011:103). A bivariate analysis was consequently conducted using a Pearson product-moment correlation (see Table 6) to indicate the relationship between behavioural intent, barriers to OHS compliance (resource and human factors), and actual behaviour. These relationships provided a basis for the multivariate analysis.

Table 6 shows significant relationships between the various factors as follows (Esterhuyzen 2017):

- There was a small negative relationship between behavioural intent and resource barriers, $r=-0.12, n=350$, $p \leq 0.05$, with resource barriers negatively affecting behavioural intent with regard to OHS.

- There was a small negative relationship between behavioural intent and human factor barriers, $r=-0.20$, $n=350, p \leq 0.05$, with human factor barriers negatively affecting behavioural intent with regard to OHS.

- There was a medium positive relationship between behavioural intent and actual behaviour, $r=0.43, n=350$, $p \leq 0.05$, with behavioural intent positively affecting actual behaviour related to OHS.

- There was a strong positive relationship between resource barriers and human barriers, $r=0.74, n=350, p \leq 0.05$, with high levels of resource barriers being associated with high levels of human factor barriers.

- There was a medium negative relationship between resource barriers and actual behaviour, $r=-0.21, n=350$, $p \leq 0.05$, with actual behaviour related to OHS negatively affecting resource barriers.

- There was a medium negative relationship between human factor barriers and actual behaviour, $r=-0.32, n=$ $350, p \leq 0.05$, with actual behaviour related to OHS negatively affecting human factor barriers.

Based on these correlations it can be deduced that all included factors were positively or negatively related in various degrees (small, $r=0.10-0.29$; medium, $r=0.30-0.49$ or large, $r=0.50-1.0)$ to one another (Pallant 2011:103).

In summary, the predetermined barriers were experienced at various levels in terms of their effects on small businesses. In addition to these barriers, additional barriers were indicated and rated by small business owners and/or managers, but these barriers were not included in the analysis because the respondents felt that no specific additional barrier seemed to jeopardise their compliance with OHS directives. The exploratory factor analysis indicated barriers to OHS compliance as related to human factors and lack of resources. The Pearson product-moment correlation, used to explore the relationship between continuous variables and to obtain an indication of the direction and strength of the relationship, confirmed the negative effect of barriers to actual compliance with OHS directives.

\section{Conclusion and implications}

Various important conclusions can be drawn from the findings of this study, thus contributing to the growing body of knowledge on OHS in South African small businesses. The additional employment created by small businesses leads to additional challenges with regard to OHS in the workplace (Mayhew 2000:302). It is estimated that small businesses will contribute $90 \%$ of new jobs in South Africa by the year 2030 (Groepe 2015). Emphasis is being placed on increasing penalties for non-compliance with OHS directives as well as on holding individual managers liable for OHS accidents in the workplace (Loosemore \& Andonakis 2007:581). The Occupational Health and Safety Act 83 of 1993 of South Africa is currently being reviewed, with one of the proposed changes being to increase fines and penalties for non-compliance with its directives. Small business compliance with OHS requirements, which seems inadequate in the South African context, might contribute to economic growth, job creation and advancement of the economic environment (DoL 2013:1). Successful management of small businesses requires compliance with applicable legislation, also with regard to OHS. Proper identification of barriers to OHS compliance in small businesses is necessary in order to deal effectively with such barriers and to prevent barriers from leading to noncompliance.

The study reported in this article has found, through analysis of the quantitative data, that the barriers to OHS compliance in small businesses can be ascribed to human factors and a lack of resources. Significant relationships between behavioural intent, human and resource barriers, and actual behaviour have been proven, thereby indicating that a reduction of the barriers to OHS compliance might enhance positive behaviour towards OHS compliance. Therefore, it can be concluded that initiatives to reduce perceived barriers to OHS compliance need to be explored with a view to enhancing OHS compliance and small business sustainability. There also appears to be a need for the South African

TABLE 6: Pearson product-moment correlation

\begin{tabular}{|c|c|c|c|c|}
\hline Factors & $\begin{array}{l}\text { Behavioural intent with regard to } \\
\text { occupational health and safety }\end{array}$ & Resource barriers & Human factor barriers & $\begin{array}{l}\text { Actual behaviour related to } \\
\text { occupational health and safety }\end{array}$ \\
\hline $\begin{array}{l}\text { Behavioural intent with regard to } \\
\text { occupational health and safety }\end{array}$ & 1 & $-0.12 *$ & $-0.20 * *$ & $0.43 * *$ \\
\hline Human factor barriers & $-0.20 * *$ & $0.74 * *$ & 1 & $-0.32 * *$ \\
\hline $\begin{array}{l}\text { Actual behaviour related to } \\
\text { occupational health and safety }\end{array}$ & $0.43 * *$ & $-0.21 * *$ & $-0.32 * *$ & 1 \\
\hline
\end{tabular}

Source: Adapted from Esterhuyzen, E., 2017, 'Occupational health and safety: A compliance management framework for small businesses in South Africa', PhD thesis, Department of Business Management, University of South Africa, Pretoria

*, Correlation is significant at the 0.05 level (2-tailed); **, Correlation is significant at the 0.01 level (2-tailed). 
government to assist small business owners and / or managers in overcoming the barriers to OHS compliance. However, small business owners and/or managers also need to address those barriers that they can overcome themselves. In correspondence with relevant literature, small business owners and/or managers need to be shown how OHS compliance can improve their business performance and reduce direct and indirect costs associated with accidents in the workplace (Loosemore \& Andonakis 2007:584). The question to answer is no longer if small businesses can afford OHS compliance, but rather if they can afford not to comply.

This study met all applicable criteria for scientifically validated research, but further research could benefit from adapting the methodology used in this study to provide for even better or more valid results. The inclusion of employees could allow for more than employer-related OHS aspects to be included. The inclusion of all nine provinces in South Africa will allow for a comparative analysis between the provinces.

Also, the questionnaire as single measuring instrument did not allow for data and methodological triangulation, which might be explored in further studies. The limited, nonprobability sample did not represent the total population (all small business owners and/or managers in all nine provinces of South Africa), thus not allowing for full generalisation.

\section{Recommendations for further research}

Research that could follow on this study needs to obtain accurate figures of OHS incidents in small businesses in South Africa with a view to enhancing the body of knowledge of safety management in the South African context. Also, as indicated above, a comparative analysis between OHS in small businesses in all nine provinces of South Africa could provide more insight into OHS in small businesses. With the success of small businesses being largely dependent on the competency of the owner/manager, the development of their competencies will provide small businesses with sustainable competitive advantage (Irene 2017). Applicable OHS training for small businesses should therefore be developed and further investigated, with specific reference to determining the effectiveness of such intervention in terms of OHS compliance and barriers to compliance.

\section{Acknowledgements}

The research for this article was undertaken at the University of South Africa during the author's PhD studies, available here: http:/ /hdl.handle.net/10500/23028.

\section{Competing interests}

The author declares that she has no financial or personal relationship that may have inappropriately influenced her in writing this article.

\section{Author's contributions}

E.E. is the sole author of this article.

\section{Funding}

This research received no specific grant from any funding agency in the public, commercial, or not-for-profit sectors.

\section{Data availability statement}

Data sharing is not applicable to this article as no new data were created or analysed in this study.

\section{Disclaimer}

The views and opinions expressed in this article are those of the author and do not necessarily reflect the official policy or position of any affiliated agency of the author.

\section{References}

Ahonen, G. \& Hussi, T., 2012, 'Economics of occupational health and safety', African Newsletter on Occupational Health and Safety 22(1), 4-5.

Ajzen, I. \& Sheikh, S., 2013, 'Action versus inaction: Anticipated affect in the theory of planned behaviour', Journal of Applied Social Psychology 43, 155-162. https:// doi.org/10.1111/j.1559-1816.2012.00989.x

Chen, J.K.C. \& Zorigt, D., 2013, 'Managing occupational health and safety in the mining industry', Journal of Business Research 66, 2321-2331. https://doi.org/10.1016/j. jbusres.2012.04.013

Companies and Intellectual Property Commission (CIPC), 2013, Annual Report 2012/2013, viewed 17 October 2014, from http://www.cipc.co.za/files/9513/9989/7347/CIPC ANNUAL_REPORT_2013.pdf.

Cooper, D.R. \& Schindler, P.S., 2011, Business research methods, 11th edn., McGrawHill, Boston, MA.

Department of Labour (DoL), 2013, Let's make compliance with OHS a norm to save resources for job creation on 27 March 2013, viewed 08 May 2018, from http://www.labour.gov.za/DOL/media-desk/media-statements/2013/ let2019s-make-compliance-with-ohs-a-norm-to-save-resources-for-jobcreation-labour.

Esterhuyzen, E., 2017, 'Occupational health and safety: A compliance management framework for small businesses in South Africa', PhD thesis, Department of Business Management, University of South Africa, Pretoria.

Floyde, A., Lawson, G., Shalloe, S., Eastgate, R. \& D'Cruz, M., 2013, 'The design and implementation of knowledge management systems and e-learning for improved occupational health and safety in small to medium sized enterprises', Safety Science 60, 69-76. https://doi.org/10.1016/j.ssci.2013.06.012

Fuller, C.W. \& Vassie, L.H., 2004, Health and safety management, Prentice Hall, London.

Goetsch, D.L., 2014, The basics of occupational safety: A guide for safety management, Pearson, London.

Groepe, F., 2015, The role of small business in the economy, viewed 05 October 2018, from https://www.resbank.co.za/Lists/Speeches/Attachments/452/Role $\% 20$ of $\% 20$ small\%20business $\% 202015 \% 20$.pdf.

Hale, A. \& Borys, D., 2013, 'Working to rule, or working safely? Part 1: A state of the art review', Safety Science 55, 207-221. https://doi.org/10.1016/j.ssci.2012.05.011

Hasle, P., Kines, P. \& Andersen, L.P., 2009, 'Small enterprise owners' accident causation attribution and prevention', Safety Science 47, 9-19. https://doi.org/10.1016/j. ssci.2007.12.005

Henning, S. \& Akoob, K., 2017, 'Motivational factors affecting informal women entrepreneurs in North-West province', The Southern African Journal of Entrepreneurship and Small Business Management 9(1), a91. https://doi. org/10.4102/sajesbm.v9i1.91

Hermanus, M.A., 2007, 'Occupational health and safety in mining - status, new developments, and concerns', The Journal of the Southern African Institute of Mining and Metallurgy 107(8), 531-538.

International Labour Organization (ILO), 2014, Creating safe and healthy workplaces for all, viewed 14 August 2015, from http://www.ilo.org/wcmsp5/ groups/public/---dgreports/---dcomm/---publ/documents/publication/ scms_305423.pdf.

Irene, B.N.O., 2017, 'Women entrepreneurship in South Africa: Understanding the role of competencies in business success', Southern African Journal of Entrepreneurship and Small Business Management 9(1), a121. https://doi org/10.4102/sajesbm.v9i1.121

Kent, P., 2013, SureSwipe MD: Laws kill small businesses, viewed 19 March 2014, from: http://www.fin24.com/Entrepreneurs/News/SureSwipe-MD-Laws-kill-smallbusinesses-20130604.

Loosemore, M. \& Andonakis, N., 2007, 'Barriers to implementing OHS reforms - the experiences of small subcontractors in the Australian Construction Industry', International Journal of Project Management 25, 579-588. https://doi. org/10.1016/j.ijproman.2007.01.015 
Markowitz, K.J. \& Gerardu, J.A., 2012, 'The importance of the judiciary in environmental compliance and enforcement', Pace Environmental Law Review 29(2), 537-554.

Mashwama, N., Aigbavboa, C. \& Thwala, W., 2018, 'Occupational health and safety challenges among small and medium sized enterprise contractors in South Africa', Online, viewed 05 October 2018, from https://link springer. com/chapter/10.1007/978-3-319-94000-7_7.

Maxey, H., 2013, Safety and small business, The Compass - American Society for Safety Engineers, Chicago, IL, pp. 12-13.

Mayhew, C., 2000, 'OHS in Australian "micro" small businesses: Evidence from nine research studies', Journal of Occupational Health and Safety 16(4), 297-305.

Mojapelo, T.J. \& Kok, L., 2017, 'Adherence to occupational health and safety standards: the case of a South African steel processing company', African Journal of Governance and Development 6(1), 51-71.

National Planning Commission, 2014, National Development Plan 2030, Government Printer, Pretoria.

Niu, S., 2010, 'Ergonomics and occupational safety and health: An ILO perspective' Applied Ergonomics 41(6), 744-753. https://doi.org/10.1016/j.apergo.2010.03.004

Okoye, P.U. \& Okolie, K.C., 2014, 'Exploratory study of the cost of health and safety performance of building contractors in South East Nigeria', British Journal of Environmental Sciences 2(1), 21-33.

Othman, A.A.E., 2012, 'A study of the causes and effects of contractor's noncompliance with the health and safety regulations in the South African construction industry', Architectural Engineering and Design Management 8 , 180-191. https://doi.org/10.1080/17452007.2012.683242

Pallant, J., 2011, SPSS survival manual: A step by step guide to data analysis using SPSS, 4th edn., Allen and Unwin, Crows Nest, NSW.

Pillay, K.R., 2014, 'The costs of construction accidents', Unpublished master's thesis, Cape Peninsula University of Technology, Bellville.
Probst, T.M., Graso, M., Estrada, A.X. \& Greer, S., 2013, 'Consideration of future safety consequences: A new predictor of employee safety', Accident Analysis and consequences: A new predictor of employee safety', Accident
Prevention 55, 124-134. https://doi.org/10.1016/j.aap.2013.02.023

Reason, J., 2005, Managing the risk of organisational accidents, Ashgate, Burlington.

Reason, J., 2007, Human error, University Press, Cambridge.

Semboja, H.H.H., Ahonen, G. \& Hussi, T., 2012, 'Microeconomics of firms compliant with occupational safety and health', African Newsletter on Occupational Health and Safety 22(1), 6-9.

Starren, A., Hornikx, J. \& Luijters, K., 2013, 'Occupational safety in multicultural teams and organisations: A research agenda', Safety Science 52, 43-49. https://doi. org/10.1016/j.ssci.2012.03.013

Stranks, J., 2010, Health and safety at work: An essential guide for managers, 9th edn., Kogan Page, London.

Struwig, F.W. \& Lillah, R., 2017, 'South African small and medium-sized enterprise owners' intention to implement an environmental management system', Southern African Journal of Entrepreneurship and Small Business Management 9(1), a104. https://doi.org/ 10.4102/sajesbm.v9i1.104

Van Vuuren, J. \& Alemayehu, B.Z., 2018, 'The role of entrepreneurship in transforming efficiency economies into innovation-based economies', Southern African Journal of Entrepreneurship and Small Business Management 10(1), a140. https://doi. org/10.4102/sajesbm.v10i1.140

Wilson, K., 2018, Can you afford non-compliance? viewed 03 October 2018, from https://jesi.io/can-afford-non-compliance-jesi.

World Health Organization (WHO), 2007, Employment conditions and health inequalities, viewed 17 August 2015 from http://who.int/social_determinants/ resources/articles/emconet_who_report.pdf?ua=1.

World Health Organization (WHO), 2017, Workplace health promotion, viewed 15 February 2017, from http://www.who.int/occupational health/topics /workplace/en/indexi.html. 